\title{
Raquianestesia total após anestesia peridural lombar com ropivacaína a $0,5 \%$ para abdominoplastia
}

\author{
Centro Médico de Sousas, Campinas, São Paulo
}

INTRロDUÇÃa

Por causa das doses excessivamente grandes de anestésico local necessárias para o bloqueio peridural, em comparação com a raquianestesia, a injeção subaracnóidea acidental, que leva à raquianestesia total, é um risco sempre presente.

RELATI DO CASD

Paciente do sexo feminino com 48 anos, $153 \mathrm{~cm}, 91 \mathrm{Kg}$, índice de massa corpórea (IMC) = 38,88, P2 (antigo ASA II), com diabetes mellitus e hipertensão arterial controlada com medicação. Programada para abdominoplastia e correção de hérnia umbilical. Realizada monitorização com cardioscópio, oxímetro de pulso e esfigmomanômetro. Venóclise com cateter teflon $18 \mathrm{G}$, sendo em seguida administrado $5 \mathrm{mg}$ de midazolam IV. Com a paciente sentada, foi feita punção lombar com agulha de Stephen Edward Tuohy 17 G entre os segmentos L1-L2, utilizando-se o sinal da perda da resistência (Achille Mario Dogliotti). O procedimento de punção foi difícil, mas o sinal foi nítido e não houve gotejamento de liquor. Injetado, sem resistência, $40 \mathrm{ml}$ de ropivacaína a $0,5 \%$ com $100 \mathrm{mcg}$ de fentanil. Imediatamente após a injeção, a paciente apresentava-se apnéica, inconsciente, midriática, $\mathrm{PA}=90 / 60 \mathrm{mmHg}$, pulso $56 \mathrm{bpm}, \mathrm{SpO}_{2} 100 \%$ e sem alteração no ritmo cardíaco. Foi intubada e mantida em ventilação controlada com $\mathrm{O}_{2}$ a $100 \%$. A cirurgia teve duração de $240 \mathrm{~min}$ e, durante todo o procedimento, foram administradas apenas doses fracionadas de $5 \mathrm{mg}$ de efedrina. Aos $260 \mathrm{~min}$, a paciente abriu os olhos e iniciou respiração espontânea e aos 300 min, já consciente, foi extubada. Apresentava boa força muscular em membros superiores e bloqueio parcial em membros inferiores (Bromage I), que desapareceu aos $340 \mathrm{~min}$. A paciente não referiu nenhuma lembrança do ato cirúrgico, não apresentou cefaléia pós-raquianestesia e teve boa evolução.

DIScUSรÃa

Embora esses acidentes sejam extremamente dramáticos e realmente ameacem a vida, a grande maioria pode ser tratada com êxito, desde que o diagnóstico e o tratamento sejam rápidos.

REFERÊNCIAS

. Delfino J, Vale N. Anestesia peridural, atualizaçăo e perspectiva. São Paulo: Atheneu; 2000:55-6.

2. Souza KM, et al. Raquianestesia total após anestesia peridural torácica para colocaçāo de prótese de mama e abnominoplastia. Relato de Caso. Rev Bras Anesth. 2004; 54:216.

Endereço para correspondência: José Tocantins Viana

Rua Giuseppe Beltramelli, $s / n^{\circ}-$ Sousas

Campinas (SP) - CEP 13105-512 